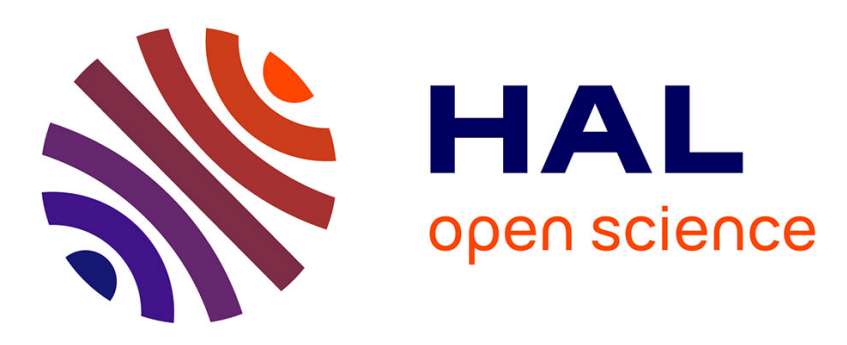

\title{
Characteristics of zirconium and niobium contacts on boron-doped diamond
}

M. Davydova, A. Taylor, P. Hubík, L. Fekete, L. Klimša, David Trémouilles, A. Soltani, Vincent Mortet

\section{- To cite this version:}

M. Davydova, A. Taylor, P. Hubík, L. Fekete, L. Klimša, et al.. Characteristics of zirconium and niobium contacts on boron-doped diamond. Diamond and Related Materials, 2018, 83, pp.184-189. 10.1016/j.diamond.2018.02.009 . hal-01956850

\author{
HAL Id: hal-01956850 \\ https://hal.laas.fr/hal-01956850
}

Submitted on 11 Feb 2019

HAL is a multi-disciplinary open access archive for the deposit and dissemination of scientific research documents, whether they are published or not. The documents may come from teaching and research institutions in France or abroad, or from public or private research centers.
L'archive ouverte pluridisciplinaire HAL, est destinée au dépôt et à la diffusion de documents scientifiques de niveau recherche, publiés ou non, émanant des établissements d'enseignement et de recherche français ou étrangers, des laboratoires publics ou privés. 


\title{
Characteristics of zirconium and niobium contacts on boron-doped diamond
}

\author{
M. Davydova*, ${ }^{\text {, A. Taylor }}{ }^{1}$, P. Hubík ${ }^{1}$, L. Fekete ${ }^{1}$, L. Klimša ${ }^{1}$, D. Trémouilles ${ }^{2}$, \\ A. Soltani ${ }^{3}$, V. Mortet ${ }^{1,4}$ \\ ${ }^{1}$ Institute of Physics of the Czech Academy of Sciences, Prague, Czech Republic \\ ${ }^{2}$ LAAS-CNRS, Université de Toulouse, CNRS, Toulouse, France \\ ${ }^{3}$ LN2, Université de Sherbrooke, Sherbrooke, QC, Canada \\ ${ }^{4}$ Czech Technical University in Prague, Faculty of Biomedical Engineering, Kladno, Czech \\ Republic
}

\begin{abstract}
Formation of ohmic contacts on boron-doped diamond using zirconium and niobium has been studied in comparison to the commonly used titanium or tantalum contacts. Metal contacts were fabricated using standard micro-fabrication technologies on epitaxial layers with different boron concentrations. Room temperature specific contact resistance was determined using the circular Transmission Line Model after annealing at various temperatures. The specific contact resistance varies considerably with boron concentration and annealing temperature. Zirconium and niobium form ohmic contacts on highly boron-doped diamond after high-temperature annealing with a specific contact resistance comparable to that of titanium and tantalum contacts. Furthermore, we observed zirconium contacts showed better thermal stability up to $700{ }^{\circ} \mathrm{C}$ upon high-temperature annealing compared to titanium and other metal contacts. Finally, these These results emphasize the potential of zirconium for the formation of ohmic contacts on boron-doped diamond.
\end{abstract}

Keywords: Ohmic contact, boron-doped diamond, circular transmission line model, zirconium, niobium, titanium

* Corresponding author

E-mail address: davydova@fzu.cz (M. Davydova)

\section{Introduction}

Diamond is a semiconductor with unique properties [1], which has been foreseen as an advantageous replacement for silicon in the fabrication of high frequency and high power devices such as high voltage Schottky diodes [2,3] and more recently MOSFETs [4] and other electronic devices [5-8]. Stable ohmic contacts with a low specific contact resistance are crucial to limit electric losses in the operation of electronic power devices. Numerous factors, such as the nature of the metal [9-16], the doping level [12], the surface pre-treatment $[9,17-$ 19], the crystalline orientation [16], and the annealing time and temperature [12,20-22] are important in the formation of ohmic or Schottky contacts. The ohmic behavior of the contacts is generally asseciated related to carbide formation [11-13,23-25]. A large variety of carbide forming metals have already been studied for the fabrication of ohmic contacts on boron (B) doped diamond [10,11,26-30]. Titanium (Ti) is generally preferred for this purpose.

With the aim of studying impurity impact ionization and avalanche effects in B-doped diamond in high electric fields [31,32], we searched carbide forming refractory metals with a high chemical affinity to carbon, similar to titanium, capable of forming good ohmic contacts, 
which could withstand high current densities and high temperatures. Niobium $(\mathrm{Nb})$, tantalum (Ta) and zirconium (Zr) are refractory metals with a Gibbs free energy for carbide formation close to that of Ti $[33,34]$. While Ta has been already studied, the formation of ohmic contacts on B-doped diamond using $\mathrm{Nb}$ or $\mathrm{Zr}$ has not, according to our knowledge, been reported in the literature. On the contrary, $\mathrm{Zr}$ has been reported to form Schottky contacts [2,35]. In this work, we studied the formation of ohmic contacts on B-doped diamond using $\mathrm{Zr}$ and $\mathrm{Nb}$ metals in comparison to the well-studied $\mathrm{Ti}$ and Ta metals. Epitaxial B-doped diamond layers were grown by microwave plasma enhanced chemical vapor deposition with various B concentrations. Metal contacts were patterned by evaporation and standard lithography processes. The current-voltage $(I-V)$ characteristics of different metal contacts were measured at room temperature, after annealing at various temperatures, and for different B concentrations. The diamond layers' resistivity, contact resistance, and specific contact resistance were determined using the circular Transmission Line Model (c-TLM) [36,37].

\section{Material and methods}

B-doped epitaxial diamond layers were grown in a microwave plasma enhanced chemical vapor deposition (MW PECVD) AX5010 reactor using a methane, hydrogen and trimethylborane gas mixture. The boron to carbon ratio $(\mathrm{B} / \mathrm{C}$ ratio) in the gas phase has been varied from $500 \mathrm{ppm}$ to $20,000 \mathrm{ppm}$ to obtain B-doped epitaxial diamond layers between a few $10^{19} \mathrm{~cm}^{-3}$ to a few $10^{21} \mathrm{~cm}^{-3}$, i.e. from the semiconductor conduction region below metallic transition up to highly doped diamond with metallic conduction. B-doped epitaxial diamond layers, with $\mathrm{B} / \mathrm{C}$ ratios of up to $6000 \mathrm{ppm}$, were grown on $3 \times 3 \times 0.8 \mathrm{~mm}^{3}$ (100)-oriented highpressure high-temperature (HPHT) grown synthetic single crystal diamond substrates using the process reported in Ref. [38]. Layers grown using this process exhibit nearly defect-free growth with a very low roughness of $0.2 \mathrm{~nm}$ and $1 \mathrm{~nm}$ over areas of $5 \times 5 \mu \mathrm{m}^{2}$ and $90 \times 90 \mu \mathrm{m}^{2}$, respectively (see Figure 1). Above the threshold of B/C 6000 ppm, epitaxial diamond growth is no longer sustained on (100)-oriented substrates. Hence B-doped epitaxial diamond layers with $\mathrm{B} / \mathrm{C}=20,000 \mathrm{ppm}$ were grown on $2 \times 2 \times 0.8 \mathrm{~mm}^{3}$ (111)-oriented HPHT grown synthetic single crystal diamond substrates using deposition conditions reported in Table 1. In contrary to B-doped epitaxial diamond layers grown on (100)-oriented substrates, layers grown on (111)-oriented substrates were not etched in an oxygen-hydrogen plasma before diamond deposition. Prior to Before and after MW PECVD deposition, samples were cleaned in a hot admixture of sulfuric acid and potassium nitrate for $10 \mathrm{~min}$. The samples were then rinsed with hot deionized water, acetone and isopropyl alcohol in an ultrasonic bath for $10 \mathrm{~min}$ and finally dried with clean compressed air. Several layers were grown with the same B/C ratio to enable the study of the properties of contacts fabricated with the four different metals. Thicknesses of the B-doped epitaxial diamond layers, used to compute the layer resistivity, was determined from double mass measurement using a high precision ME5 microbalance (Sartorius).

Circular Transmission Line Model test structures were fabricated by photolithography and metal evaporation. c-TLM structures were preferred as they are easily realized without the need of a MESA etch to prevent current spreading in linear TLM structures. The electrodes were patterned by the lift-off technique using a positive photoresist ma-P 1210 from Microresist technology exposed with a mask-less laser lithography system: Microwriter ML 
from the Lot Oriel company. Details of the lithography process are described in ref. [39]. The spacing between the inner circular electrodes $(150 \mu \mathrm{m}$ in diameter) and the outer electrodes varies between 10 and $60 \mu \mathrm{m}$ (see Figure 1). Metals were deposited by e-beam evaporation in an Edwards Auto 500 vacuum coater. $\mathrm{Zr}, \mathrm{Nb}$, Ta and Ti $10 \mathrm{~nm}$ thick contacts were capped using a $90 \mathrm{~nm}$ thick gold layer with a $10 \mathrm{~nm}$ thick platinum inter-diffusion layer. The $I-V$ characteristics of fabricated c-TLM structures were characterized using a computer controlled Agilent 4142B modular DC source/monitor and a probe station Suss Microtech PA-200. Electrical characteristics were measured at room temperature for as-deposited and consecutively annealed contacts with increasing temperature: $200{ }^{\circ} \mathrm{C}, 400{ }^{\circ} \mathrm{C}, 500{ }^{\circ} \mathrm{C}, 600{ }^{\circ} \mathrm{C}$ and $700{ }^{\circ} \mathrm{C}$. Samples were annealed at low pressure in a rapid thermal annealing system, ASOne from Annealsys for $20 \mathrm{~min}$ in a flow of nitrogen.

The resistance of c-TLM structures has been calculated using linear least squares fitting $I-V$ characteristics. Due to the circular geometry, the non-linear variation of the resistance as a function of the gap spacing is linearized using a correction factor (see Figure 2). The correction factor $(c)$ is a function of the inner electrode radius $(R)$ and the inter-electrode spacing $(s)$ as described in equation (1).

$$
c=\frac{R}{s} \ln \frac{[R+s]}{R}
$$

Linear least squares fitting of corrected resistance enables the determination of the contact resistance $\left(R_{c}\right)$, transfer length $\left(L_{T}\right)$, and the diamond sheet resistance $\left(R_{s h}\right)$ from the Y-axis intercept, the $\mathrm{X}$-axis intercept and the slope, respectively [36].

\section{Results and discussion}

The resistivity of B-doped epitaxial diamond layers extracted from c-TLM as a function of the $\mathrm{B} / \mathrm{C}$ ratio is reported in Fig. 3. Based on the ref. [40,41], one can cautiously assume conservation of the $\mathrm{B} / \mathrm{C}$ ratio from the gas phase to the solid phase during deposition to estimate boron incorporation into grown layers. This assumption is supported by the quantitative agreement of measured values with values from the literature [42,43]. The resistivity drops from a few $\Omega . \mathrm{cm}$ in the region of incomplete ionization, i.e. when $\mathrm{B} / \mathrm{C}=500 \mathrm{ppm}$, to a few $10 \mathrm{~s}$ of $\mathrm{m} \Omega . \mathrm{cm}$ for $\mathrm{B} / \mathrm{C} \geq 2000 \mathrm{ppm}$ in the region of metallic conduction. The higher resistivity values of epitaxial layers prepared with $B / C=20,000 \mathrm{ppm}$ are attributed to the known poorer conduction properties of B-doped epitaxial diamond layers grown on (111)-oriented substrates [40]. As deposited $\mathrm{Ta}, \mathrm{Nb}$ and $\mathrm{Zr}$ contacts fabricated on B-doped epitaxial diamond layers grown with a $\mathrm{B} / \mathrm{C}$ ratio of $500 \mathrm{ppm}$ exhibit symmetric but non-ohmic $I-V$ characteristics, which is in contrary to $\mathrm{Ti}$ contacts (not shown). $\mathrm{Nb}$ and $\mathrm{Zr}$ form ohmic contacts only after high temperature annealing $\left(\geq 400^{\circ} \mathrm{C}\right)$. The evolution of $I-V$ characteristics with annealing temperature of layers grown at high $\mathrm{B}$ concentration $(\mathrm{B} / \mathrm{C}=20,000 \mathrm{ppm})$ is shown in Fig. 4. Remarkably, as deposited Ta also formed ohmic contact on highly doped layers $(B / C=20,000$ ppm) with a ca. $2 \times 10^{-4} \Omega . \mathrm{cm}^{2}$ specific contact resistance. The total resistance of Ti contacts suddenly increases after high temperature annealing $\left(\geq 600{ }^{\circ} \mathrm{C}\right)$. This increase in resistance indicates a degradation of the specific contact resistance. The variations of the calculated specific contact resistance as a function of the annealing temperature and the B concentration for the different fabricated metal contacts are reported in Fig. 5 and Fig. 6. Fig. 6 shows that a clear decrease in the specific contact resistance with the rising B concentration is observed for all metals. The specific contact resistance drops by almost four orders of magnitude from a few 
$\Omega . \mathrm{cm}^{2}$ to a few $10^{-4} \Omega . \mathrm{cm}^{2}$ and below as the B concentration increases by a factor of 40 from $500 \mathrm{ppm}$ to $20,000 \mathrm{ppm}$. The lowest contact resistance of $4 \times 10^{-5} \Omega . \mathrm{cm}^{2}$ was obtained for an asdeposited Ti contact on a layer grown with $\mathrm{B} / \mathrm{C}=20,000 \mathrm{ppm}$. Note that all contacts on heavily B-doped epitaxial diamond layers, i.e. above the metallic transition [44], exhibited low specific contact resistance values of about $10^{-4} \Omega . \mathrm{cm}^{2}$ after optimal annealing. The same decrease in specific contact resistance of $\mathrm{Ti}$ and Mo contacts on polycrystalline B-doped diamond was reported by Nakanishi et al. who also reported a linear correlation between specific contact resistance and the resistivity of the doped layer [22]. The strong influence of acceptor concentration $\left(\mathrm{N}_{\mathrm{a}}\right)$ is associated to tunneling transport at the contact interface [22] and the $\mathrm{N}_{\mathrm{a}}{ }^{-}$ $1 / 2$ decrease of the Schottky contact depletion width [45]. The specific contact resistance of Ti and Ta contacts decreases steadily with annealing temperature between $200^{\circ} \mathrm{C}$ and $500^{\circ} \mathrm{C}$. However, B-doped epitaxial diamond layers grown at a high B/C ratio, e.g. ef 20,000 ppm, show that a rapid increase in the specific contact resistance is observed after annealing at higher temperatures, which indicates attributed to a degradation of the ohmic contacts. This effect is also observed in $\mathrm{Nb}$ contacts. Similar degradation of ohmic contacts observed for $\mathrm{Ti}$ and $\mathrm{Mo}$ contacts on B-doped diamond upon annealing was reported by Johnston et al. [14]. Whilst less pronounced, degradation of $\mathrm{Ti}$, Ta and $\mathrm{Nb}$ contacts is also observed on layers with lower $\mathrm{B}$ concentrations. In contrary to this, the On the contrary, Zr metal-zirconium contacts show a steady improvement of $\rho_{c}$ values with increasing temperature up to $700^{\circ} \mathrm{C}$. The higher This observed better thermal stability of $\mathrm{Zr}$ contacts suggests that they might have a longer lifetime before failure than conventionally used Ti contacts. The optimal specific resistance values of $\mathrm{Ti}, \mathrm{Nb}, \mathrm{Zr}$, and $\mathrm{Ta}$ contacts for the various $\mathrm{B}$ concentrations studied in this work and their respective annealing temperature are summarized in Table 2. These results clearly show that $\mathrm{Nb}$ and $\mathrm{Zr}$ metals form ohmic contacts with specific contact resistance comparable to the ordinarily used Ti or Ta metals. Specific resistances reported in this work are larger than reported values from the literature [22]. This difference is attributed to the absence of an amorphisation process step in the preparation of the metal contacts $[16,19,46,47]$.

\section{Conclusion}

The properties of $\mathrm{Ti}, \mathrm{Ta}, \mathrm{Zr}$ and $\mathrm{Nb}$ metal contacts on $\mathrm{B}$-doped epitaxial diamond layers have been measured and compared using circular transmission line model for various B concentrations and different consecutive annealing temperatures. Doped diamond layer resistivity values determined from c-TLM are consistent with data from the literature. Formation of ohmic contact using $\mathrm{Zr}$ and $\mathrm{Nb}$ has been demonstrated with specific contact resistance comparable to the ones of $\mathrm{Ti}$ and $\mathrm{Ta}$ after high-temperature annealing. The specific contact resistance varies significantly with B concentration, nature of the metal contact, and annealing temperature. Finally, we observed $\mathrm{Zr}$ contacts on highly boron doped diamond exhibit better stability upon high-temperature annealing compared to other studied metallic contacts, especially titanium contacts. This result suggests that $\mathrm{Zr}$ contacts might advantageously replace conventional $\mathrm{Ti}$ contacts for a long lifetime and high-temperature applications of diamend devices.

\section{Acknowledgements}

This work was financially supported by the project 17-05259S of Czech Science Foundation, the French-Czech Project Barrande 35785SC - 7AMB16FR004 of the Czech Ministry of 
Education, Youth and Sports, the MEYS CR FUNBIO CZ.2.16/3.1.00/21568 (SEM purchase), LO1409, LM2015088 projects (SEM maintenance) and the J.E. Purkyně fellowship awarded to V. Mortet by the Czech Academy of Sciences.

\section{References}

[1] R. Kalish, Diamond as a unique high-tech electronic material: difficulties and prospects, J. Phys. D. Appl. Phys. 40 (2007) 6467-6478. doi:10.1088/0022-3727/40/20/S22.

[2] A. Traoré, P. Muret, A. Fiori, D. Eon, E. Gheeraert, J. Pernot, Zr/oxidized diamond interface for high power Schottky diodes, Appl. Phys. Lett. 104 (2014). doi:10.1063/1.4864060.

[3] T. Teraji, S. Koizumi, Y. Koide, T. Ito, Electric field breakdown of lateral schottky diodes of diamond, Japanese J. Appl. Physics, Part 2 Lett. 46 (2007). doi:10.1143/JJAP.46.L196.

[4] Y. Jingu, K. Hirama, H. Kawarada, Ultrashallow TiC source/drain contacts in diamond MOSFETs formed by hydrogenation-last approach, IEEE Trans. Electron Devices. 57 (2010) 966-972. doi:10.1109/TED.2010.2043311.

[5] M. Davydova, M. Stuchlik, B. Rezek, K. Larsson, A. Kromka, Sensing of phosgene by a porouslike nanocrystalline diamond layer with buried metallic electrodes, Sensors Actuators B Chem. 188 (2013) 675-680. doi:10.1016/j.snb.2013.07.079.

[6] H. Umezawa, M. Nagase, Y. Kato, S.I. Shikata, High temperature application of diamond power device, Diam. Relat. Mater. 24 (2012) 201-205. doi:10.1016/j.diamond.2012.01.011.

[7] M. Davydova, A. de los Santos Pereira, M. Bruns, A. Kromka, E. Ukraintsev, M. Hirtz, C. Rodriguez-Emmenegger, Catalyst-free site-specific surface modifications of nanocrystalline diamond films via microchannel cantilever spotting, RSC Adv. 6 (2016) 57820-57827. doi:10.1039/C6RA12194B.

[8] W. Wang, C. Hu, S.Y. Li, F.N. Li, Z.C. Liu, F. Wang, J. Fu, H.X. Wang, Diamond based fieldeffect transistors of $\mathrm{Zr}$ gate with sinx dielectric layers, J. Nanomater. 2015 (2015). doi:10.1155/2015/124640.

[9] K. Das, V. Venkatesan, K. Miyata, D.L. Dreifus, J.T. Glass, A review of the electrical characteristics of metal contacts on diamond, Thin Solid Films. 212 (1992) 19-24. doi:10.1016/0040-6090(92)90494-V.

[10] G. Kawaguchi, J. Nakanishi, A. Otsuki, T. Oku, M. Murakami, Dependence of contact resistance on metal electronegativity for B-doped diamond films, J. Appl. Phys. 75 (1994) 5165-5170. doi:10.1063/1.357009.

[11] Y. Koide, M. Yokoba, A. Otsuki, F. Ako, T. Oku, M. Murakama, Carrier transport mechanisms through the metal /p-type diamond semiconductor interface, Diam. Relat. Mater. 6 (1997) 847851.

[12] M. Werner, Job R.,Denisenko A., Zaitsev A., Fahrner A.R., Johnston C., Chalker P.R., B.-G. I.M., How to fabricate low-resistance metal-diamond contacts, Diam. Relat. Mater. 5 (1996) 723-727.

[13] C. Zhen, Y. Wang, S. He, Q. Guo, Z. Yan, Y. Pu, Ohmic contacts to boron-doped diamond, in: Opt. Mater. (Amst)., 2003: pp. 117-121. doi:10.1016/S0925-3467(03)00071-5.

[14] C. Johnston, P.R. Chalker, I.M. Buckley-Golder, M. van Rossum, M. Werner, E. Obermeier, High temperature contacts to chemically vapour deposited diamond films-reliability issues, Mater. Sci. Eng. B. 29 (1995) 206-210. doi:10.1016/0921-5107(94)04033-Z.

[15] D. Doneddu, O.J. Guy, R.M. Baylis, L. Chen, P.R. Dunstan, P.A. Mawby, C.F. Pirri, S. Ferrero, D. Twitchen, A. Tajani, M. Schwitters, SNOM Investigation of Surface Morphology Changes 
during Cr/Au Contact Fabrication on Single-Crystal CVD Diamond, Mater. Sci. Forum. 527529 (2006) 1587-1590. doi:10.4028/www.scientific.net/MSF.527-529.1587.

[16] Y.T. Cheng, S.J. Lin, J. Hwang, Effect of diamond facet on the electrical properties of Pt/BF +2 ion implanted polycrystalline diamond contacts, Appl. Phys. Lett. 63 (1993) 3344-3346. doi:10.1063/1.110165.

[17] S.A. Grot, G.S. Gildenblat, C.W. Hatfield, C.R. Wronski, a. R. Badzian, T. Badzian, R. Messier, The Effect of Surface Treatment on the Electrical Properties of Metal Contacts to Boron-Doped, IEEE Electron Device Lett. 11 (1990) 100. doi:10.1109/55.46942.

[18] J.F. Prins, Preparation of ohmic contacts to semiconducting diamond, J. Phys. D. Appl. Phys. 22 (1989) 1562-1564. doi:10.1088/0022-3727/22/10/026.

[19] T. Tachibana, B.E. Williams, J.T. Glass, Correlation of the Electrical-Properties of Metal Contacts on Diamond Films With the Chemical Nature of the Metal-Diamond Interface .2. Titanium Contacts - a Carbide-Forming Metal, Phys. Rev. B. 45 (1992) 11975-11981. doi:10.1103/PhysRevB.45.11975.

[20] D.A. Evans, O.R. Roberts, G.T. Williams, A.R. Vearey-Roberts, F. Bain, S. Evans, D.P. Langstaff, D.J. Twitchen, Diamond-metal contacts: interface barriers and real-time characterization, J. Phys. Condens. Matter. 21 (2009) 364223. doi:10.1088/0953$8984 / 21 / 36 / 364223$.

[21] J.J. Chen, F. Zeng, D.M. Li, J.B. Niu, F. Pan, Deposition of high-quality zinc oxide thin films on diamond substrates for high-frequency surface acoustic wave filter applications, Thin Solid Films. 485 (2005) 257-261. doi:10.1016/j.tsf.2005.04.028.

[22] J. Nakanishi, A. Otsuki, T. Oku, O. Ishiwata, M. Murakami, Formation of ohmic contacts to ptype diamond using carbide forming metals, J. Appl. Phys. 76 (1994) 2293-2298. doi:10.1063/1.357649.

[23] Y.Y. Wang, C.M. Zhen, Z.J. Yan, Q.F. Guo, G.H. Chen, Ohmic contacts on diamond by rf sputtering and Ti-Au metallization, World. 16 (2002) 927-931.

[24] P.E. Vijoen, Reaction between diamond and titanium for ohmic contact and metallization adhesion layers, J. Vac. Sci. Technol. B Microelectron. Nanom. Struct. 12 (1994) 2997. doi:10.1116/1.587549.

[25] D.A. Evans, O.R. Roberts, G.T. Williams, A.R. Vearey-Roberts, F. Bain, S. Evans, D.P. Langstaff, D.J. Twitchen, Diamond-metal contacts: interface barriers and real-time characterization, J. Phys. Condens. Matter. 21 (2009) 364223. doi:10.1088/0953$8984 / 21 / 36 / 364223$.

[26] S. Kono, T. Teraji, H. Kodama, K. Ichikawa, S. Ohnishi, A. Sawabe, Direct determination of the barrier height of Ti-based ohmic contact on p-type diamond (001), Diam. Relat. Mater. 60 (2015) 117-122. doi:10.1016/j.diamond.2015.10.028.

[27] S. Koné, H. Schneider, K. Isoird, F. Thion, J. Achard, R. Issaoui, S. Msolli, J. Alexis, An assessment of contact metallization for high power and high temperature diamond Schottky devices, Diam. Relat. Mater. 27-28 (2012) 23-28. doi:10.1016/j.diamond.2012.05.007.

[28] M. Suzuki, T. Sakai, T. Makino, H. Kato, D. Takeuchi, M. Ogura, H. Okushi, S. Yamasaki, Electrical characterization of diamond PiN diodes for high voltage applications, Phys. Status Solidi. 210 (2013) 2035-2039. doi:10.1002/pssa.201300051.

[29] G. Braunstein, R. Kalish, Effective p-type doping of diamond by boron ion implantation, J. Appl. Phys. 54 (1983) 2106-2108. doi:10.1063/1.332262.

[30] V. Mortet, O. Elmazria, W. Deferme, M. Daenen, J. D’Haen, A. Lazea, A. Morel, K. Haenen, 
M. D'Olieslaeger, Titanium nitride grown by sputtering for contacts on boron-doped diamond, Plasma Process. Polym. 4 (2007) 139-143. doi:10.1002/ppap.200730506.

[31] V. Mortet, A. Soltani, Impurity impact ionization avalanche in p-type diamond, Appl. Phys. Lett. 99 (2011). doi:10.1063/1.3662403.

[32] V. Mortet, D. Tremouilles, J. Bulir, P. Hubik, L. Heller, E. Bedel-Pereira, A. Soltani, Peculiarities of high electric field conduction in p-type diamond, Appl. Phys. Lett. 108 (2016). doi:10.1063/1.4946853.

[33] S.R. Shatynski, The thermochemistry of transition metal carbides, Oxid. Met. 13 (1979) 105118.

[34] H. Shiomi, H. Nakahata, T. Imai, Y. Nishibayashi, N. Fujimori, Electrical Characteristics of Metal Contacts To Boron-Doped Diamond Epitaxial Film, Jpn. J. Appl. Phys. 1. 28 (1989). files/178/full_record.html.

[35] P.K. Baumann, R.J. Nemanich, Comparison of electron affinity and Schottky barrier height of zirconium and copper-diamond interfaces, J. Vac. Sci. Technol. B. 15 (1997) 1236-1240. doi:Doi 10.1116/1.589444.

[36] J.H. Klootwijk, C.E. Timmering, Merits and limitations of circular TLM structures for contact resistance determination for novel III-V HBTs, Proc. 2004 Int. Conf. Microelectron. Test Struct. (IEEE Cat. No.04CH37516). 17 (2004) 8-13. doi:10.1109/ICMTS.2004.1309489.

[37] L.F. Lester, J.M. Brown, J.C. Ramer, L. Zhang, S.D. Hersee, J.C. Zolper, Nonalloyed Ti/Al Ohmic contacts to ntype GaN using hightemperature premetallization anneal, Appl. Phys. Lett. 69 (1996) 2737-1556. doi:10.1063/1.362816.

[38] V. Mortet, L. Fekete, P. Ashcheulov, A. Taylor, P. Hubik, D. Treumoille, E. Bedel-Pereira, (100) substrate processing optimization for fabrication of smooth boron doped epitaxial diamond layer by PECVD, in: Proc. 6th Int. Conf. Nanomater. - Nanocon 2014, 2015: pp. 115-119. http://nanocon2012.tanger.cz/files/proceedings/20/reports/3485.pdf.

[39] L. Nicolas, T. David, T. Andrew, H. Pavel, C. Joris, B. Jiri, M. Vincent, Development of $100 \mathrm{~ns}$ wide blumlein transmission line pulse generator for study of high electric field properties in boron-doped diamond, in: Proc. 9th Int. Conf. Nanomater. - Nanocon 2017, 2017: pp. 3-8.

[40] V. Mortet, M. Daenen, T. Teraji, A. Lazea, V. Vorlicek, J. D’Haen, K. Haenen, M. D'Olieslaeger, Characterization of boron doped diamond epilayers grown in a NIRIM type reactor, Diam. Relat. Mater. 17 (2008) 1330-1334. doi:10.1016/j.diamond.2008.01.087.

[41] V. Mortet, J. Pernot, F. Jomard, A. Soltani, Z. Remes, J. Barjon, J. D’Haen, K. Haenen, Properties of boron-doped epitaxial diamond layers grown on (110) oriented single crystal substrates, Diam. Relat. Mater. 53 (2015) 29-34. doi:10.1016/j.diamond.2015.01.006.

[42] J.-P. Lagrange, A. Deneuville, E. Gheeraert, Activation energy in low compensated homoepitaxial boron-doped diamond films, Diam. Relat. Mater. 7 (1998) 1390-1393. doi:10.1016/S0925-9635(98)00225-8.

[43] C.E. Nebel and M.Stutzmann, Properties, growth and applications of diamond, in: M.N. Nazare (Ed.), Transp. Prop. Diam. Carr. Mobil. Resist., INSPEC, The Institution of Electrical Engineers, London, 2001: pp. 40-52.

[44] V. Venkatesan, D.M. Malta, K. Das, A.M. Belu, Evaluation of ohmic contacts formed by B+ implantation and Ti-Au metallization on diamond, J. Appl. Phys. 74 (1993) 1179-1187. doi:10.1063/1.354918.

[45] S.M. Sze, Physics of Semiconductor Devices, 2nd ed, in: New York Wiley, 1981: p. 187.

[46] G.R. Brandes, C.P. Beetz, C.F. Feger, R.W. Wright, J.L. Davidson, Ion implantation and anneal 
to produce low resistance metal-diamond contacts, Diam. Relat. Mater. 8 (1999) 1936-1943. doi:10.1016/S0925-9635(99)00161-2.

[47] M.W. Geis, M. Rothschild, R.R. Kunz, R.L. Aggarwal, K.F. Wall, C.D. Parker, K.A. McIntosh, N.N. Efremow, J.J. Zayhowski, D.J. Ehrlich, J.E. Butler, Electrical, crystallographic, and optical properties of ArF laser modified diamond surfaces, Appl. Phys. Lett. 55 (1989) 2295-2297. doi:10.1063/1.102042.

[48] T. Teraji, H. Wada, M. Yamamoto, K. Arima, T. Ito, Highly efficient doping of boron into highquality homoepitaxial diamond films, Diam. Relat. Mater. 15 (2006) 602-606. doi:10.1016/j.diamond.2006.01.011.
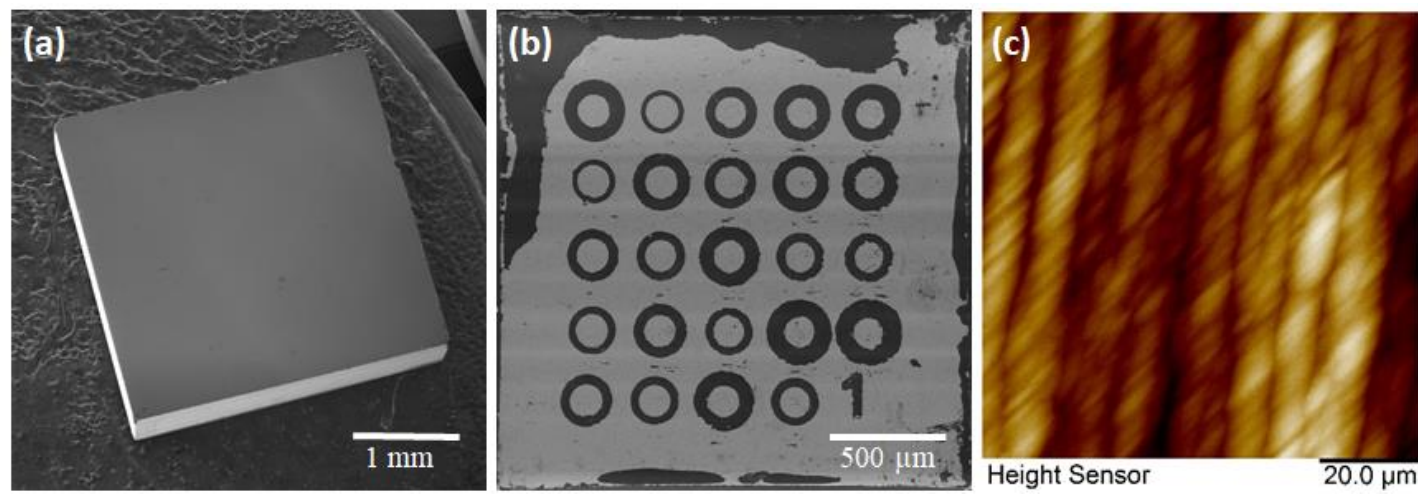

$3.4 \mathrm{~nm}$

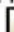

Figure 1: Scanning electron microscopy images of (a) B-doped epitaxial diamond layer on (100)-oriented HPHT substrate and (b) c-TLM structures fabricated on a Bboron-doped epitaxial diamond layer deposited on a (111)-oriented HPHT substrate. $90 \times 90 \mu \mathrm{m}^{2}$ AFM topography image of a Bboron-doped epitaxial diamond layer grown on a (100)-oriented substrate (c).

Table 1: Diamond deposition conditions

\begin{tabular}{lcccc}
\hline \hline $\begin{array}{l}\text { Substrate } \\
\text { orientation }\end{array}$ & $\begin{array}{c}\text { MW power } \\
\text { (W) }\end{array}$ & $\begin{array}{c}\text { Pressure } \\
\text { (mbar) }\end{array}$ & $\begin{array}{c}\mathbf{C H}_{\mathbf{4}} \text { in } \mathbf{H}_{\mathbf{2}} \\
\text { concentration }\end{array}$ & $\begin{array}{c}\text { Deposition } \\
\text { temperature }\left({ }^{\circ} \mathbf{C} \text { ) }\right.\end{array}$ \\
\hline$(100)$ & 700 & 100 & $1 \%$ & 1100 \\
\hline$(111)$ & 575 & 60 & $0.1 \%$ & 1000 \\
\hline
\end{tabular}




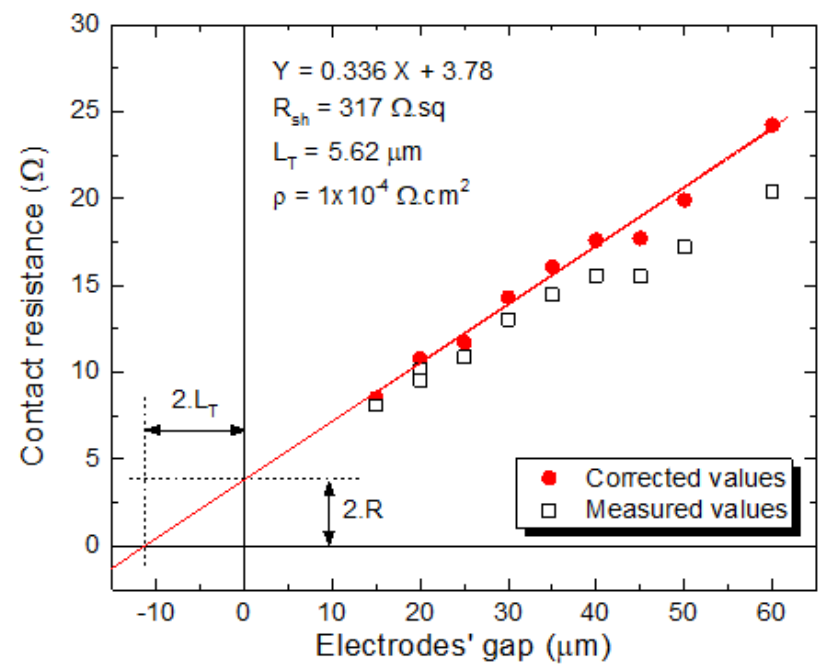

Figure 2: Total resistance vs electrodes' gap spacing before (squares) and after (red circles) correction for the circular geometry.

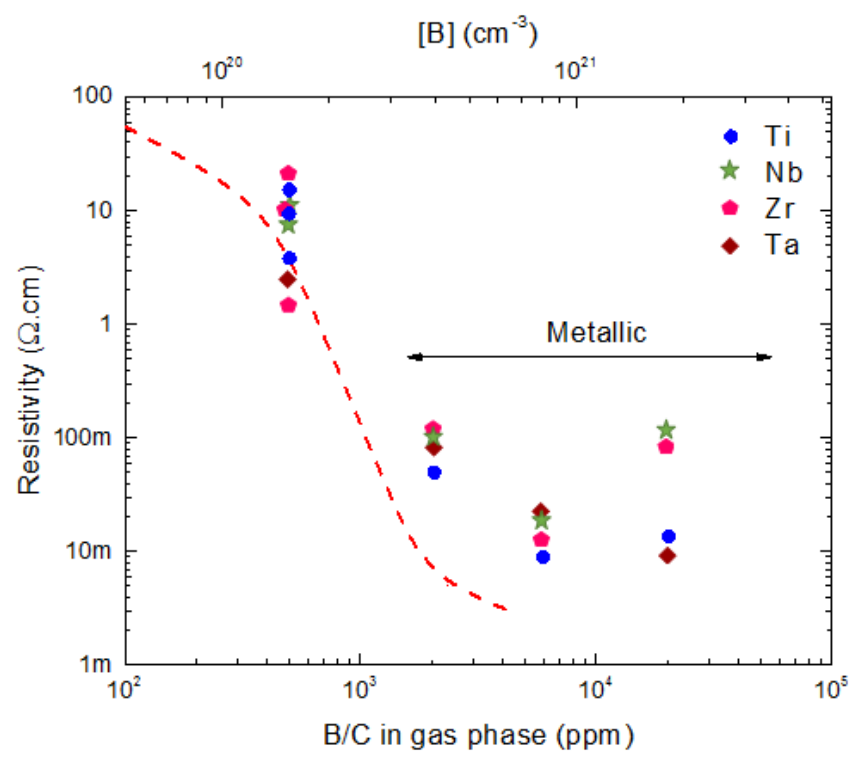

Figure 3: Room-temperature resistivity of (100) and (111) B-doped epitaxial diamond layers as a function of the boron to carbon ratio $B$ concentration in the gas phase with respect to the earbon source. Comparison between literature (red dash line) $[42,43]$ and experimental data from this study (the boron concentration ([B]) of the upper $\mathrm{X}$-axis is calculated was determined assuming conservation of $\mathrm{B} / \mathrm{C}$ ratio from the gas phase to the solid phase during diamond deposition $[41,48])$. 

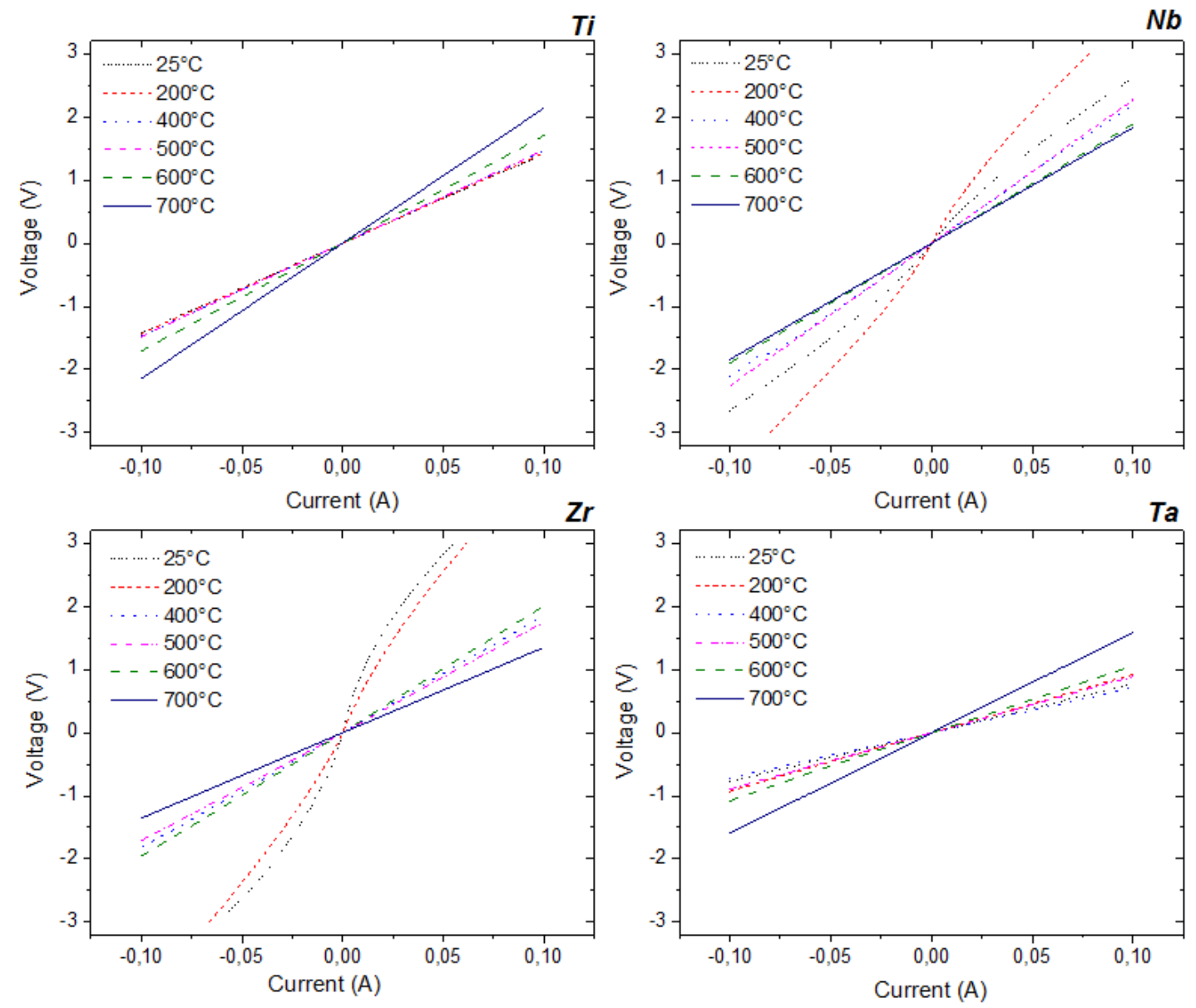

Figure 4: $\mathrm{I}-V$ characteristic of $\mathrm{Ti}, \mathrm{Nb}, \mathrm{Zr}$ and $\mathrm{Ta}$ contacts on $\mathrm{B}$-doped diamond annealed at several temperatures up to $700^{\circ} \mathrm{C}$. 

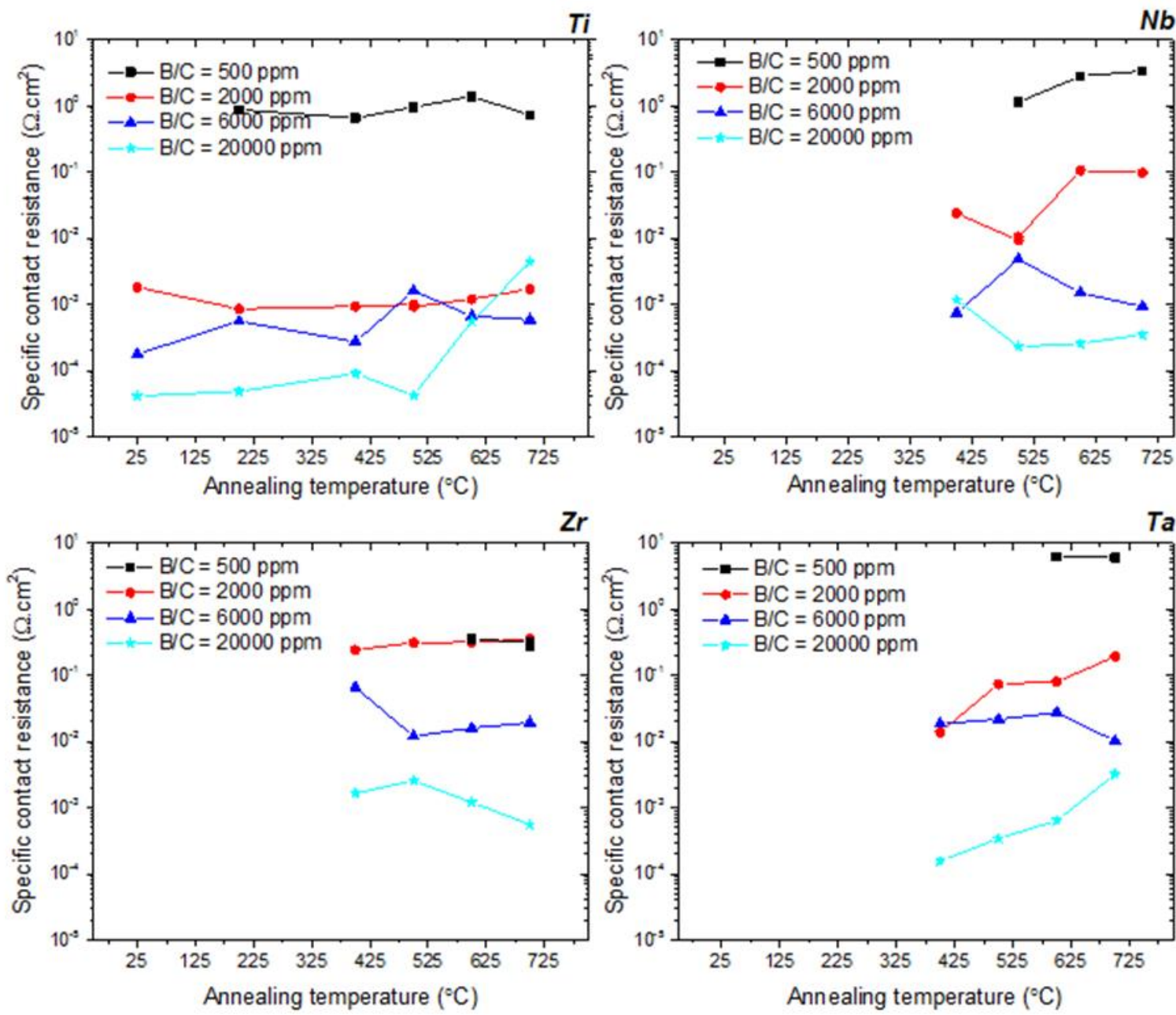

Figure 5: Specific contact resistance as a function of annealing temperature for $\mathrm{Ti}, \mathrm{Nb}, \mathrm{Zr}$, and Ta contacts to various B-doped epitaxial diamond layers.

Table 2 Optimal specific contact resistance of the $\mathrm{Ti}, \mathrm{Nb}, \mathrm{Zr}$ and $\mathrm{Ta}$ contacts for various $\mathrm{B}$ concentrations after annealing at optimal temperatures.

\begin{tabular}{lcccc}
\hline \hline $\mathrm{B} / \mathrm{C}$ vs $\boldsymbol{\rho}_{\mathbf{c}}$ & $\mathbf{T i}\left(\boldsymbol{\Omega} . \mathrm{cm}^{\mathbf{2}}\right)$ & $\mathbf{N b}\left(\boldsymbol{\Omega . c m}{ }^{\mathbf{2}}\right)$ & $\mathrm{Zr}\left(\boldsymbol{\Omega} . \mathrm{cm}^{\mathbf{2}}\right)$ & $\mathrm{Ta}\left(\boldsymbol{\Omega} . \mathrm{cm}^{\mathbf{2}}\right)$ \\
\hline $\mathbf{5 0 0} \mathbf{~ p p m}$ & $1.4\left(600^{\circ} \mathrm{C}\right)$ & $1.1\left(500^{\circ} \mathrm{C}\right)$ & $0.3\left(700^{\circ} \mathrm{C}\right)$ & $5.9\left(700^{\circ} \mathrm{C}\right)$ \\
\hline $\mathbf{2 , 0 0 0} \mathbf{~ p p m}$ & $8.5 \times 10^{-4}\left(200^{\circ} \mathrm{C}\right)$ & $9.7 \times 10^{-2}\left(500^{\circ} \mathrm{C}\right)$ & $0.2\left(400^{\circ} \mathrm{C}\right)$ & $1.3 \times 10^{-2}\left(400^{\circ} \mathrm{C}\right)$ \\
\hline $\mathbf{6 , 0 0 0} \mathbf{~ p p m}$ & $1.7 \times 10^{-4}\left(25^{\circ} \mathrm{C}\right)$ & $1.4 \times 10^{-4}\left(25^{\circ} \mathrm{C}\right)$ & $1.2 \times 10^{-2}\left(500^{\circ} \mathrm{C}\right)$ & $12.7 \times 10^{-3}\left(700^{\circ} \mathrm{C}\right)$ \\
\hline $\mathbf{2 0 , 0 0 0} \mathbf{~ p p m}$ & $4.1 \times 10^{-5}\left(500^{\circ} \mathrm{C}\right)$ & $2.5 \times 10^{-4}\left(600^{\circ} \mathrm{C}\right)$ & $5.5 \times 10^{-4}\left(700^{\circ} \mathrm{C}\right)$ & $1.5 \times 10^{-4}\left(400^{\circ} \mathrm{C}\right)$ \\
\hline
\end{tabular}



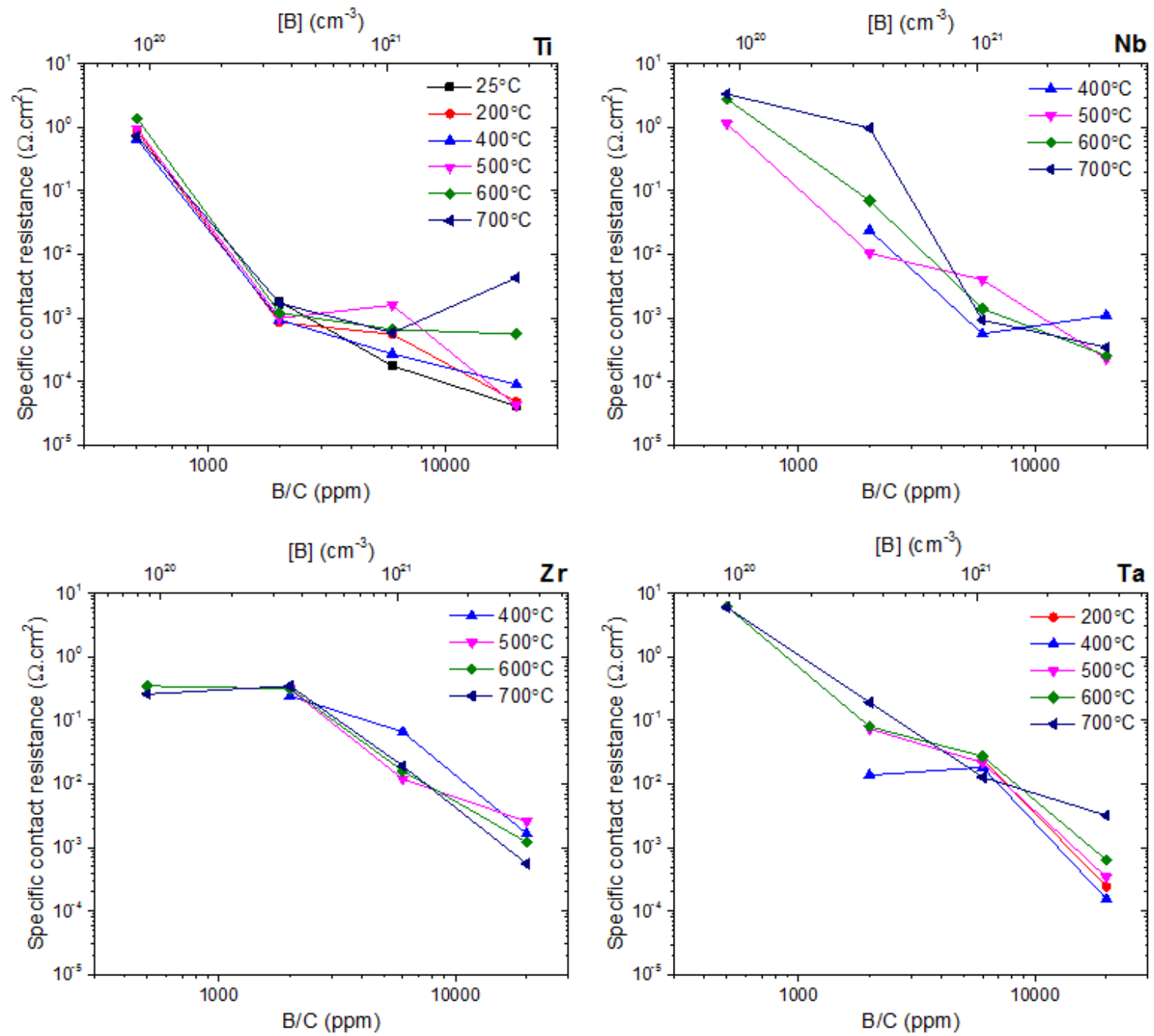

Figure 6: Specific contact resistances of $\mathrm{Ti}, \mathrm{Nb}, \mathrm{Zr}$, and $\mathrm{Ta}$ contacts annealed at different temperatures as a function of $\mathrm{B} / \mathrm{C}$ ratio during deposition and boron concentration $[\mathrm{B}]$ (the boron concentration ([B]) of upper $\mathrm{x}$-axis is calculated assuming conservation of $\mathrm{B} / \mathrm{C}$ ratio from the gas phase to the solid phase during diamond deposition $[41,48])$ = 